\title{
Snow grain-size determination from Landsat imagery over Terre Adélie, Antarctica
}

\author{
Barbara Bourdelles AND Michel Fily
}

Laboratoire de Glaciologie et de Géophysique de l'Environnement du CNRS, B.P. 96, F-38400 Saint Martin d'Hères Cédex, France

\begin{abstract}
A Landsat Thematic Mapper scene over Terre Adélie, Antarctica, is used to estimate the snow grain-size. New calibration coefficients are computed for the TM scene, using sea-water reflectance. Topographic effects are corrected with the visible band TM2. Atmospheric effects are taken into account. The snow theoretical reflectance is calculated with the Wiscombe and Warren (1980) model. Estimated snow grain-sizes are similar to those given in the literature.
\end{abstract}

\section{INTRODUCTION}

Monitoring of snow is important for the assessment of water resources and for its role in Earth's radiation balance. Certain characteristics of snow can be obtained from its spectral signature in the visible, infrared and microwave domains. This is particularly of interest when studying the immense Antarctic ice sheet where ground

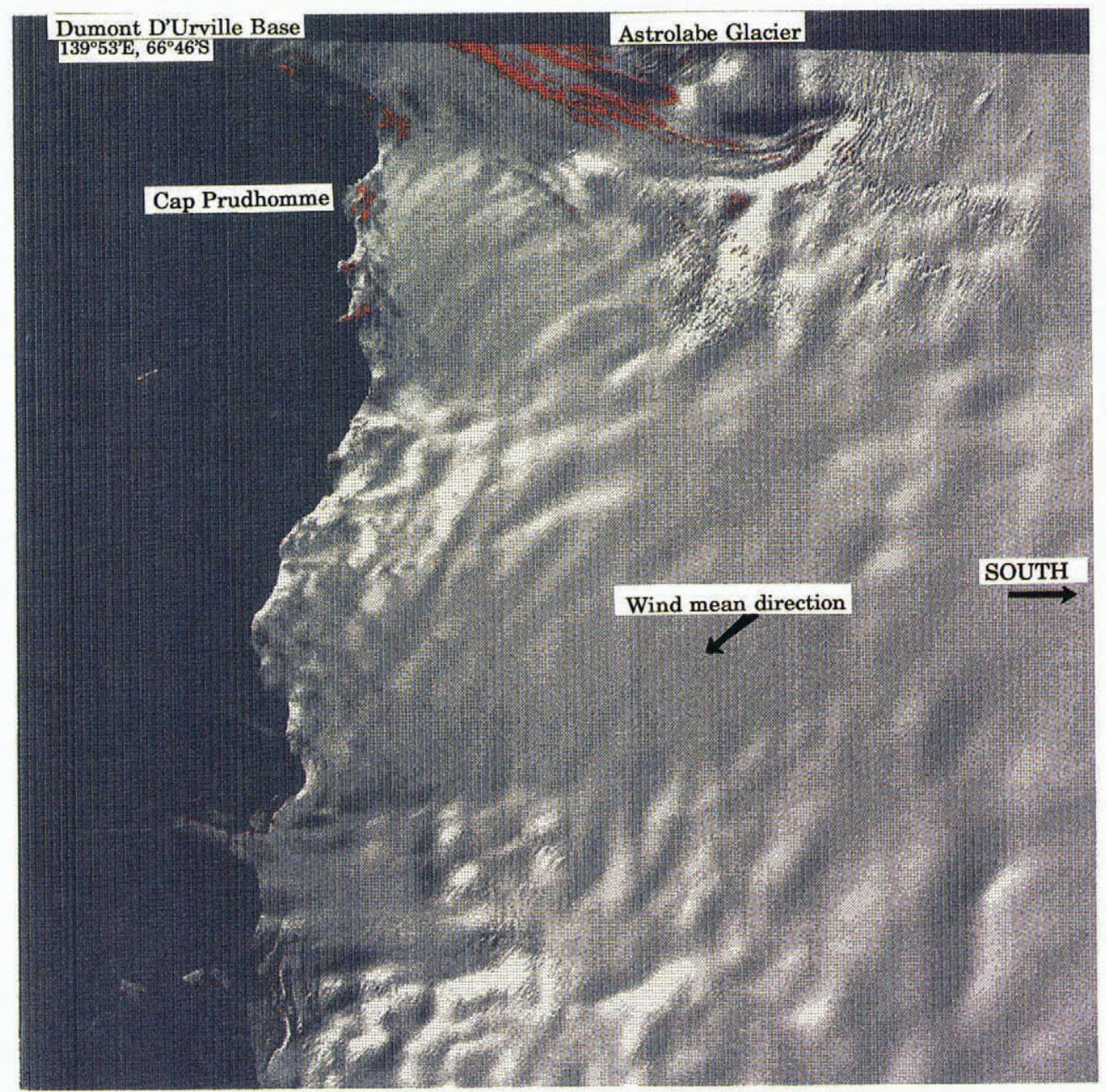

Fig. 1. The $1000 \times 1000$ pixels part of the Landsat TM2 scene (path 107, row 086) over Terre Adélie on 14 January 1989. Dumont d'Urville base is located at $139^{\circ} 53^{\prime} \mathrm{E}, 66^{\circ} 46^{\prime} \mathrm{S}$. Red dots show points where blue ice appears (see text). 
Table 1. Landsat TM channels and their wavelengths in $\mu m$

Channel

\author{
Wavelength
}

$\mu \mathrm{m}$

$\begin{array}{ll}\text { TM1 } & 0.45-0.52 \\ \text { TM2 } & 0.52-0.60 \\ \text { TM3 } & 0.63-0.69 \\ \text { TM4 } & 0.76-0.90 \\ \text { TM5 } & 1.55-1.75 \\ \text { TM7 } & 2.08-2.35\end{array}$

data are sparse. For example, the reflectance of snow in the near-infrared range is known to be dependent on snow grain-size (Dozier, 1984, 1989; Hyvarinen and Lammasniemi, 1987). The objective of the research presented here is to use this dependence to estimate snow grain-size from satellite imagery.

\section{LANDSAT DATA}

The spectral bands provided by the Landsat TM (Thematic Mapper) are well suited to this kind of study (Table 1). Three visible and three infrared channels are available. We therefore acquired a scene over Terre Adélie near the French Dumont d'Urville base $\left(139^{\circ} 53^{\prime} \mathrm{E}, 66^{\circ} 46^{\prime} \mathrm{S}\right)$. This location was chosen because ground data are available along the route from Dumont d'Urville to Dome C located far inland $\left(124^{\circ} \mathrm{E}, 71^{\circ} 4^{\prime} \mathrm{S}\right)$.

Figure 1 shows a part of the scene $-1000 \times 1000$ pixels corresponding to $30 \times 30 \mathrm{~km}$. This small part of the scene was used at full resolution and the entire scene was studied at a lower resolution $(120 \mathrm{~m}$ instead of $30 \mathrm{~m})$. Unfortunately, TM1 and TM3 were saturated for snow and have not been used. The coast consists mainly of high ice cliffs. Only a few locations are not covered by ice or snow. Cap Prudhomme is a rocky cape indicated in Figure 1; it is the start of the Dumont d'Urville-Dome C route. Large undulations are seen on the ice sheet, related to the bedrock topography. Astrolabe Glacier is quite different from the surrounding snow. Its basin is apparent and crevasse zones are very clear. The scene was taken on 14 January 1989. During the austral summer, the sun shines all day long and snow metamorphism can result from long exposure to solar radiation. Katabatic winds are also a major component of the Terre Adélie coastal weather, blowing from the top of the ice sheet down to the sea at speeds that can reach more than $55 \mathrm{~m} \mathrm{~s}^{-1}$. Their mean direction is southeastward. On 14 January 1989, the sky was clear and the wind was blowing at only $7 \mathrm{~m} \mathrm{~s}^{-1}$. There was a small $2 \mathrm{~h}$ snowfall $2 \mathrm{~d}$ before, after at least 2 weeks without snowfall. Therefore, the studied area was covered by a thin layer of new snow over a large amount of older snow.

\section{SNOW APPARENT REFLEGTANGE AT THE TOP OF THE ATMOSPHERE}

\section{Atmospheric transfer model}

In order to simulate the atmospheric effect on the signal reaching the sensor, the $5 \mathrm{~S}$ model "Simulation of the Satellite Signal in the Solar Spectrum" from the Laboratoire d'Optique Atmosphérique, Lille, France was used (Tanré and others, 1986). The pressure and temperature profiles at Dumont d'Urville station for 15 January 1989 at 0000 h GMT were available from MétéoFrance. These measured profiles were used because the standard sub-arctic winter atmosphere was incorrect by about $20 \mathrm{~K}$ and led to very different atmospheric effects. The Landsat scene was acquired $1 \mathrm{~h}$ earlier on 14 January at 2300 h GMT. For ozone and water vapour, the data from the standard sub-artic winter sub-routine was used. Because the highest part of the scene is at more than $1000 \mathrm{~m}$, the influence of the surface elevation on the atmospheric transfer was tested and found to be negligible ( $<1 \%$ on the reflectance).

\section{Snow-reflectance model}

Wiscombe and Warren (1980) proposed two snow reflectance models based on Mie scattering theory and on the $\delta$ Eddington approximation in order to account for the extreme forward anisotropy of scattering by snow particles. Snow grains are assumed to be spherical with a radius $r$, and the snow cover is considered as a homogeneous layer of ice spheres. The first model deals with pure snow. It needs only a few input parameters: snow grain-size $r$, incidence angle $\theta_{\mathrm{i}}$ for irradiance, the ratio of diffuse to direct solar irradiance and the wavelength. It agrees well with observations, except in the visible part where trace amounts of impurities can reduce the albedo (Sergent and others, 1993). Therefore, a second model is proposed for snow containing impurities (Warren and Wiscombe, 1980). On the Antarctic ice sheet the pure snow model can be used, because the amounts of dust-like particles and soot are negligible (personal communication from M. Legrand).

From this model a hemispherically integrated albedo is obtained. A Lambertian surface is assumed in order to compare this albedo with the directional reflectances measured by the satellite sensor. As insufficient measurements of the BRDF of the snow are available in the literature, it is difficult to quantify the error due to this assumption. At the time of the Landsat acquisition scene, the solar zenithal angle was $58^{\circ}$. The next important step will be to use a discrete-ordinate model (Stamnes and others, 1988) and to obtain new measurements of the BRDF of the snow.

As real snow particles are not spherical, the radius $r$ used in the Wiscombe and Warren model is called effective grain-size. Therefore, care must be taken when comparing measurements with model results. For the time being, laboratory measurements are necessary to link effective grain-size with the real grain shape depending on the type of snow (Sergent and others, 1993).

Figure 2 shows curves of reflectance versus wavelength for different grain-sizes. The effect of the chosen atmos- 

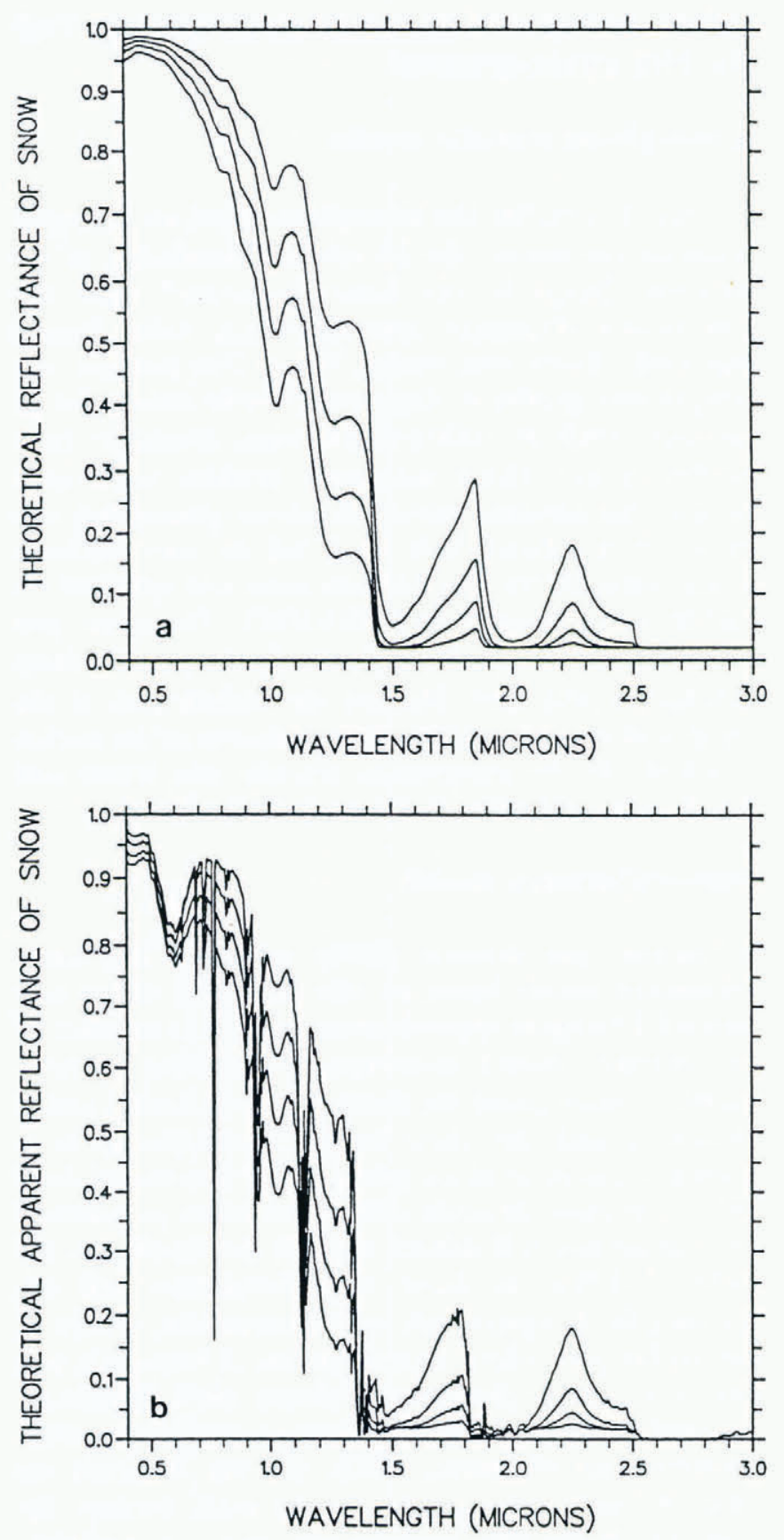

Fig. 2. Theoretical snow reflectance (a) at ground level, as modeled by Wiscombe and Warren (1980); (b) at the top of the atmosphere, based on the $5 S$ atmospheric-transfer model. Snow grain-sizes are 100, 250, 500, $1000 \mu \mathrm{m}$ from top to bottom.

phere on these curves is also shown. Snow reflectance is high in the visible part of the spectrum and is almost independent with respect to grain-size. At around $0.8 \mu \mathrm{m}$ wavelength, the reflectance curves drop to very low values. Two peaks, about 1.8 and $2.2 \mu \mathrm{m}$, are due to the variations of the ice refractive index. At these wavelengths (up to $0.8 \mu \mathrm{m}$ ) the reflectance is dependent on the grainsize. This property will be used to estimate snow grainsize from the apparent reflectance values, as the two peaks correspond respectively to channels TM5 and TM7.

Using the models described above, an integrated value of theoretical apparent reflectance at the top of the atmosphere $\rho_{\text {app }}=0.824$ was calculated for channel

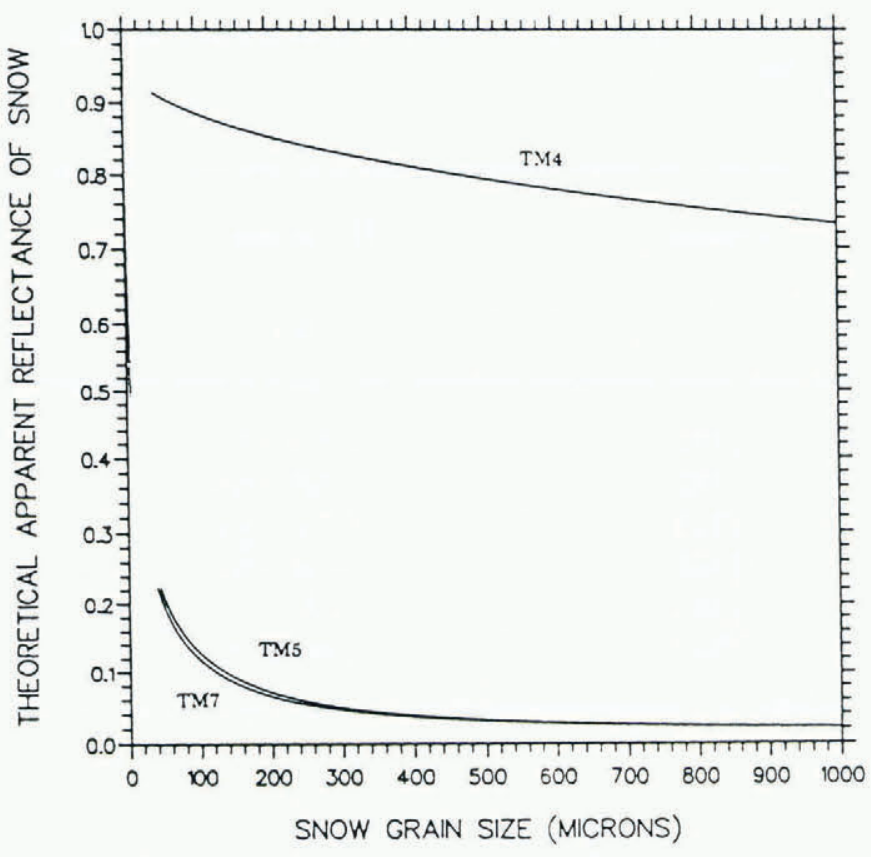

Fig. 3. Reflectance of the snow at the top of the atmosphere versus snow grain-size, for infrared channels TM4, TM5 and TM7.

TM2. The graphs of $\rho(r)$ at the top of the atmosphere, $r$, varying from 20 to $1000 \mu \mathrm{m}$ have been plotted on Figure 3 for TM4, TM5 and TM 7.

\section{LANDSAT CALIBRATION}

The Landsat data are coded on single byte numerical counts (NC) from 0 to 255 . Radiances $L_{\text {sat }}$ at satellite level are computed by:

$$
L_{\text {sat }}=a_{0}+a_{1} \mathrm{NC}
$$

where $a_{0}$ and $a_{1}$ are the calibration coefficients. Therefore, the apparent reflectance is:

$$
\rho_{\mathrm{app}}=\frac{L_{\mathrm{sat}} \pi}{E_{0} \cos \theta_{\mathrm{i}}}
$$

where $E_{0}$ is the solar irradiance in the TM channel and $\theta_{\mathrm{i}}$ is the local solar incidence angle. Solar irradiance values were computed by Markham and Barker (Dozier, 1989).

Several pairs of calibration coefficients are available. Those most often used are the pre-launch coefficients provided by EOSAT on the magnetic tape with the imagery data. From comparison with ground measurements, new calibration coefficients are provided by $\mathrm{Gu}$ and others from INRA Montfavet, France (personal communication). In this work we used the well-known reflectance of sea water in order to choose the best calibration coefficients.

For TM2 the apparent reflectance measured over the sea with the EOSAT calibration coefficients is close to the one computed with the atmopsheric profile as described above. Therefore, the EOSAT $a_{0}$ and $a_{1}$ are used for this channel.

However, neither EOSAT nor INRA calibration coefficients led to correct values of the sea-water 
reflectance in the infrared channels. Thus, new calibration coefficients were established for them. All the values are summarized in Table 2.

For the IR channels the sea-water reflectance is close to zero. Therefore, the measured apparent reflectance over the sea is the atmospheric apparent reflectance which is computed with the $5 \mathrm{~S}$ model. Then, using Equation (1), either $a_{0}$ or $a_{1}$, or both, can be modified in order to get close values between modeled and measured reflectances over the sea. For the TM4 channel, the difference between modeled and measured apparent sea reflectances is too large to be accounted for solely by atmospheric effects. We therefore kept the atmosphere as described above and tested different values for $a_{0}$ and $a_{1}$. If the $a_{1}$ coefficient is modified according to the sea-water reflectance, the resulting reflectances of the snow are unrealistic: 0.4 instead of $0.7-0.9$ (Sergent and others, 1992). Therefore $a_{0}$ was modified and plausible snow reflectances were found. The grain-sizes estimated with TM4 are very sensible to the calibration coefficient. They would have been smaller by $40 \%$ with EOSAT coefficients. The same approach was used for TM5 and TM7. However, for these two channels, the snow grainsizes estimated from EOSAT or new calibration coefficients are very similar. The difference is less than $1 \%$ for TM5 and about $5 \%$ for TM7.

\section{TOPOGRAPHIC EFFEGTS AND TM2}

According to Wiscombe and Warren's (1980) model results, the snow reflectance in channel TM2 is almost independent with respect to grain-size and solar incidence angle. An integrated value at the top of atmopshere

Table 2. Calibration coefficients $a_{0}$ and $a_{1}$ from EOSAT, INRA and this work

\section{EOSAT INRA This work}

$\begin{array}{llll}\text { TM1 } & a_{0}=-1.50 & a_{0}=-1.37 & \\ & a_{1}=0.602 & a_{1}=0.746 & \\ \text { TM2 } & a_{0}=-2.80 & a_{0}=-2.77 & a_{0}=-2.80 \\ & a_{1}=1.175 & a_{1}=1.464 & a_{1}=1.175 \\ \text { TM3 } & a_{0}=-1.12 & a_{0}=-2.08 & \\ & a_{1}=0.806 & a_{1}=1.100 & \\ \text { TM4 } & a_{0}=-1.50 & a_{0}=-2.08 & a_{0}=-5.75 \\ & a_{1}=0.815 & a_{1}=0.926 & a_{1}=0.815 \\ \text { TM5 } & a_{0}=-0.37 & a_{0}=-0.44 & a_{0}=-0.30 \\ & a_{1}=0.108 & a_{1}=0.133 & a_{1}=0.108 \\ \text { TM7 } & a_{0}=-0.15 & a_{0}=-0.19 & a_{0}=-0.06 \\ & a_{1}=0.055 & a_{1}=0.060 & a_{1}=0.055\end{array}$

of $\rho=0.824$ was calculated. The assumption was made that the variations over the scene were due to topographic effects. Hence, according to:

$$
\rho_{\text {app }}=\frac{L_{\text {sat }} \pi}{E_{0} \cos \theta_{\mathrm{i}}}=\frac{L_{\text {sat }} \pi}{E_{0} \cos \left(\theta_{\mathrm{s}}-\alpha\right)}=0.824
$$

(where $L_{\text {sat }}$ is the radiance at satellite level, $\theta_{\mathbf{s}}$ the solar zenithal angle, $\theta_{\mathrm{i}}$ the local solar incidence angle and $E_{0}$ the solar irradiance in the TM2 channel) a local slope angle $\alpha$ was deduced for each pixel. The variation of apparent reflectance $(<1 \%)$ induced by the altitude in the atmospheric correction was tested. The computed slope angles are unaffected and there is no effect on the estimated snow grain-sizes.

The calculated slopes are in good agreement with measured values along the Dumont d'Urville-Dome C route. This comparison could be done because this route and the solar-incidence vector are approximately in the same vertical plane.

In this way, the slope angle calculated for each pixel was used to correct the infrared data for topographic effects.

\section{SNOW GRAIN-SIZE DETERMINATION}

\section{Method}

In the infrared spectral range, snow reflectance depends on snow grain-size. This property was employed successively with the three infrared channels TM4, TM5 and TM7. For each pixel, the apparent reflectance is calculated from the numerical count $\mathrm{NC}$ by:

$$
\rho_{\text {app }}=\frac{\left(a_{0}+a_{1} \mathrm{NC}\right) \pi}{E_{0} \cos \left(\theta_{\mathrm{s}}-\alpha\right)}
$$

using the slope angle $\alpha$ determined with TM2. This apparent reflectance is compared with theoretical modeled reflectances $\rho(r)$ computed for different radius $r$ (Fig. 3). The snow grain-size $r$ is the radius for which $\rho_{\text {app }}=\rho(r)$.

In the above calculation, a single $\rho(r)$ curve was computed at each TM wavelength using the solar azimuthal angle as irradiance angle. However, the true irradiance angle is slightly different due to the local slope. Therefore, the curves $\rho(r)$ corresponding to the maximum slope angles appearing on the scene were computed, and for each pixel reflectance, the resulting grain-sizes were compared. The maximum error made on grain-size using this approximation is less than $15 \%$.

\section{Results}

Spatial variations of grain-sizes are very similar whether obtained from TM4, TM5 and TM7 data. Results from TM4 and TM5 are displayed in Figure 4. TM7 is not shown because it is almost identical to TM5. Snow grainsize decreases from the coast towards the ice-sheet plateau in the first kilometers and then stays almost constant.

However, as shown in the Figure 5 histograms, grainsize distribution computed with TM4 is quite different from those obtained from TM5 and TM7. With TM4, 


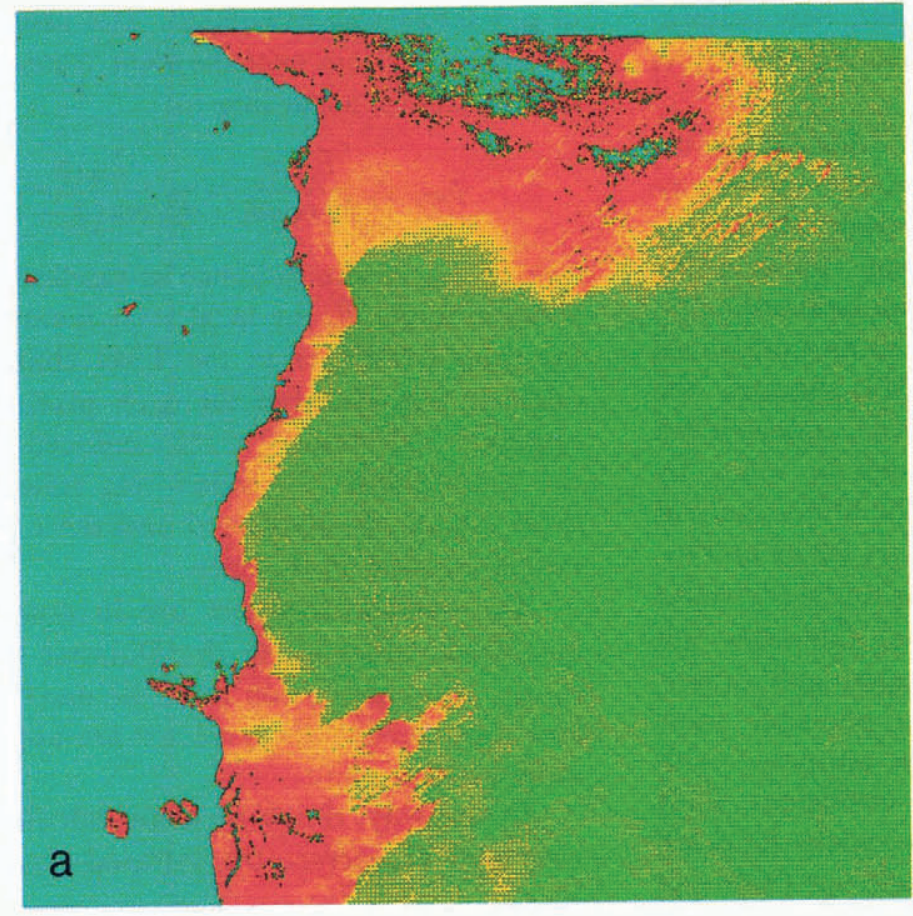

\section{TM5}

\begin{tabular}{|c|c|}
\hline ABOVE & $46 \subseteq$ \\
\hline 438 & $-46 s$ \\
\hline $406-$ & -438 \\
\hline $375-$ & -406 \\
\hline $344-$ & -375 \\
\hline $313-$ & -34 \\
\hline $281-$ & -313 \\
\hline $250-$ & -28 \\
\hline $219-$ & -250 \\
\hline $188-$ & $-21 s$ \\
\hline $156-$ & -188 \\
\hline $125-$ & -150 \\
\hline $94-$ & -125 \\
\hline 31 & \\
\hline BELOW & \\
\hline
\end{tabular}

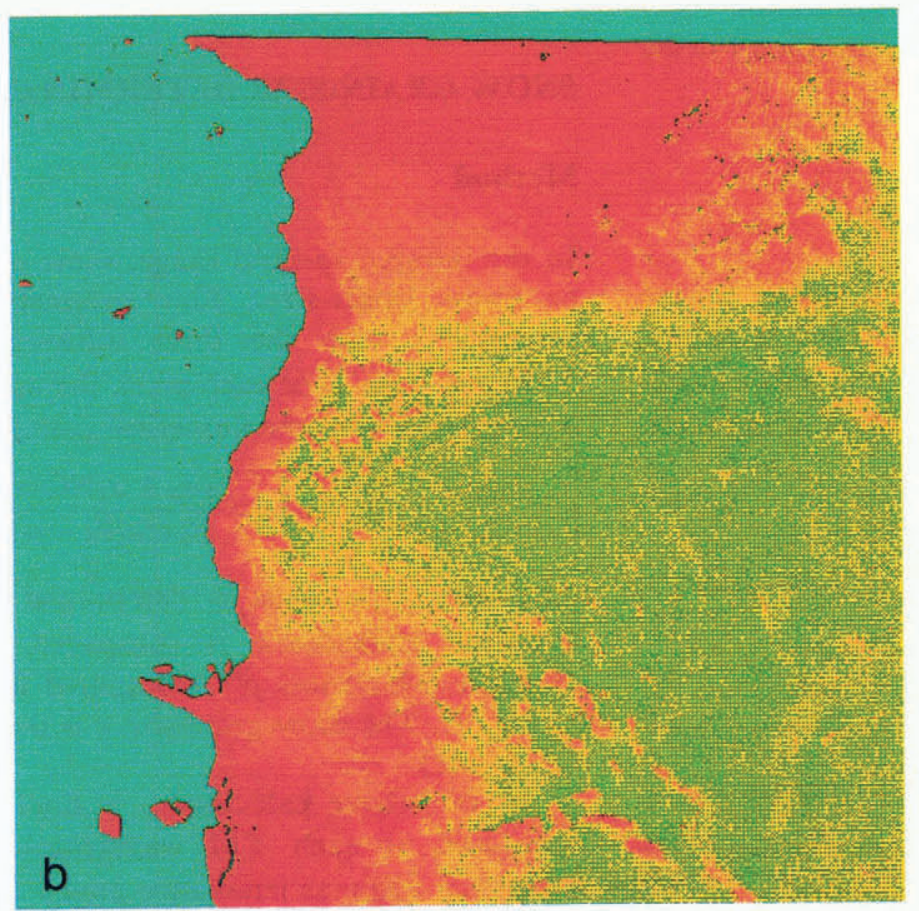

snow grain size (microns)

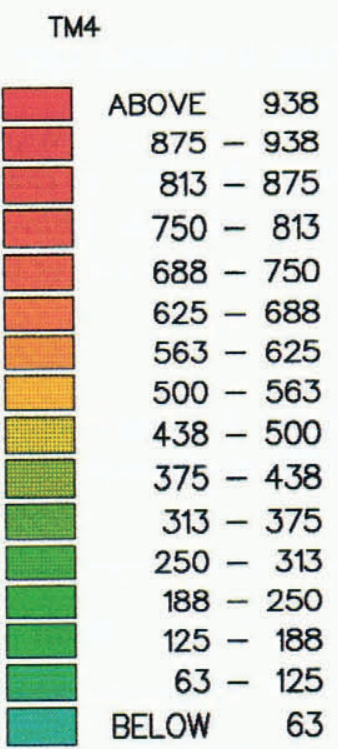

Fig. 4. Snow grain-sizes in micrometers using (a) TM5 and (b) TM4. Note the color scales.

mean grain-size is larger $(420-430 \mu \mathrm{m}$ instead of $145-$ $165 \mu \mathrm{m})$ and there is more variability. This difference could be due to the variable penetration depth of radiation depending on its wavelength. This depth is negligible for TM5 and TM7 but can reach $0.5-2.5 \mathrm{~cm}$ water equivalent depending on grain-size for TM4.

The radiation received by TM5 and TM7 therefore comes only from the upper surface grains while TM4 is sensitive to a deeper snow layer of almost $10 \mathrm{~cm}$. In this latter case, the computed snow grain-sizes are larger because the metamorphism induces the growth of the snow particles. At the time of the scene acquisition there was indeed a thin layer of new snow over a much older snow. Warren (1982) came to the same conclusion from numerical experiments and from Antarctic snow-reflectance measurements (Warren and others, 1986).

An alternate explanation would be to suppose that the atmospheric-correction model is not sufficiently accurate. By choosing an atmospheric profile with maritime aerosols, snow grain-sizes computed with TM4 would have been lower by about $50 \mu \mathrm{m}$. Introducing a small amount of soot into the atmosphere gave lower variations on the grain-sizes. As discussed previously, the error due to the Lambertian surface assumption is difficult to quantify and the amount of soot in the snow is too small to affect the results. 


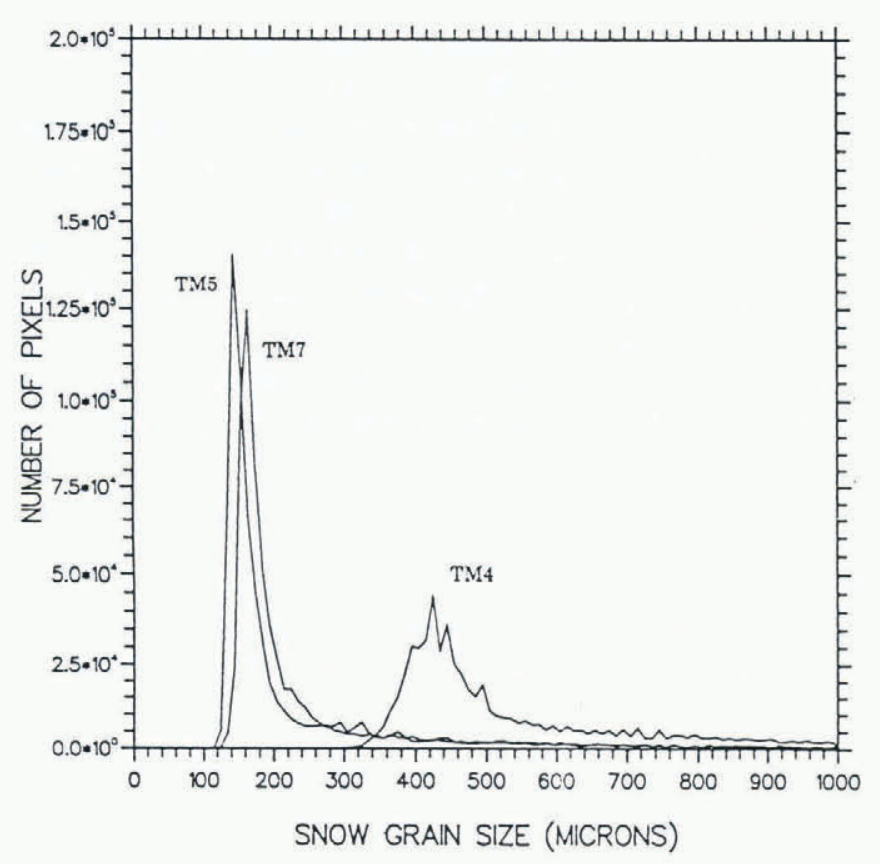

Fig. 5. Histograms of snow grain-sizes calculated with TM4, TM5 and TM7.

In order to compare our results with ground data, snow samples were collected in Terre Adélie during the 1991-92 austral summer. To prevent metamorphism, they are presently kept stored at a negative temperature in 2,2,4-trimethylpentane ("isooctane") (Brun and Pahaut, 1991). They will be analyzed in a laboratory using an image-processing device (Sergent and others, 1992) after transport to France. These measurements will be made in collaboration with the Centre d'Étude de la Neige, Grenoble, France. However, estimated grain-sizes are similar to those given in the literature (Lorius, 1963), measured in situ during the austral summer.

\section{BLUE ICE}

Along the coast, very large grain-sizes were sometimes computed because there was only ice and no snow. Grainsize is therefore meaningless along the coast. Another part of the Landsat scene study concerns the blue-ice spectral signature. A well-known blue-ice field is located near Cap Prudhomme. The corresponding pixels were extracted for the four available spectral bands. Figure 6 gives the minimal and maximal curves of blue-ice spectral reflectance with the snow spectral-reflectance curves for two grain-sizes. The overall shapes of the curves are different: blue-ice spectral reflectance has a positive concavity, in contrast with the snow-spectral reflectance.

In Figure 1, the red dots indicate pixels with spectral signatures similar to those of the Cap Prudhomme field.

\section{CONGLUSION}

Snow grain-sizes estimated from Landsat imagery are similar to those found in the literature. This work has

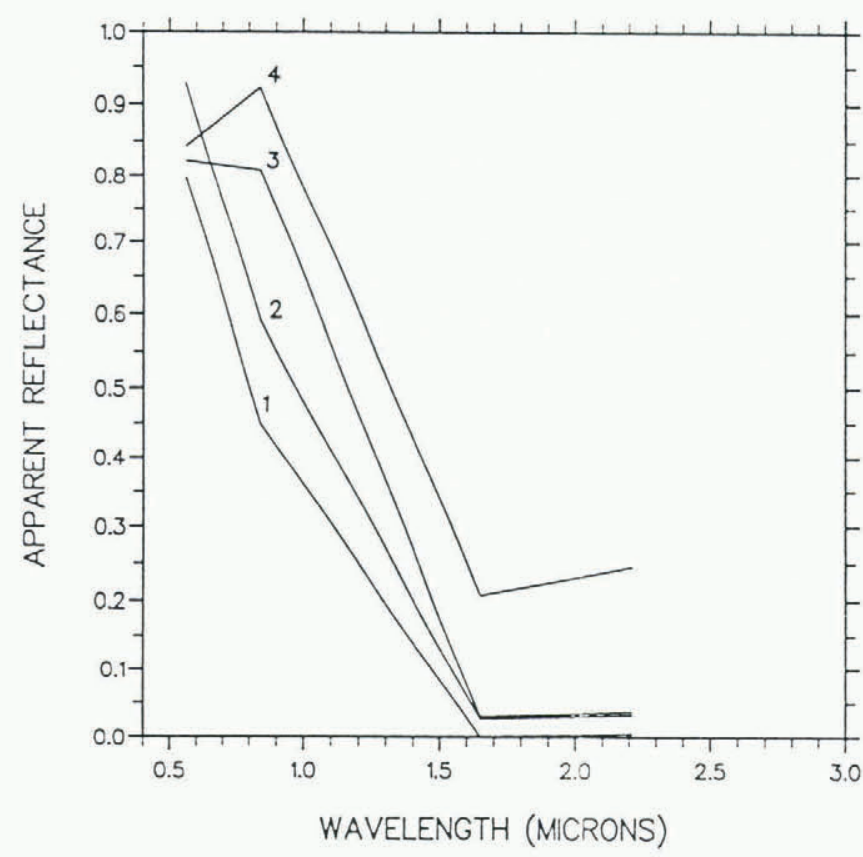

Fig. 6. Apparent reflectance of blue-ice (minimal values (1) and maximal values (2)) compared with snow reflectance at the top of the atmosphere for grain-sizes of $500 \mu \mathrm{m}$ (3) and $50 \mu \mathrm{m}$ (4).

revealed the important effect of the radiation-penetration depth. Channels TM5 and TM7 are only sensitive to the surface of the snow cover, while TM4 receives information from the top centimeters, leading to the determination of a greater grain-size. For quantitative results, two points appear to be crucial: (a) A realistic atmosphere must be used to model the atmospheric effects. (b) Above all, good calibration is necessary. Obviously, the method based on sea-water reflectance will not be applicable everywhere in Antarctica, for example on the Central Plateau.

The next step of this work on snow grain-size determination from satellite imagery will be to use a bidirectional snow-reflectance model and to extend the spatial scale. NOAA AVHRR data will be used in order to cover a much larger part of the Antarctic ice sheet.

\section{ACKNOWLEDGEMENTS}

This work was funded by Programme National de Télédétection Spatiale 1990. Helpful comments were given by the two anonymous reviewers.

\section{REFERENCES}

Brun, E. and E. Pahaut. 1992. An efficient method for a delayed and accurate characterization of snow grains from natural snowpacks. 7. Glaciol., 37(127), 420-422.

Dozier, J. 1984. Snow reflectance from Landsat 4 Thematic Mapper. IEEE Trans. Geosci. Remote Sensing, 17, 1213-1221.

Dozier, J. 1989. Spectral signature of alpine snow cover from the Landsat Thematic Mapper. Remote Sensing Environ., 28, 9-22. 
Hyvarinen, T. and J. Lammasniemi. 1987. Infrared measurement of free-water content and grain size of snow. Opt. Eng., 26(4), 342-348.

Lorius, C. 1963. Glaciologie. Terre Adélie, campagne d'été 1961-1962. Expéditions Polaires Françaises 241.

Sergent, C., E. Pougatch, M. Sudul and B. Bourdelles. 1993. Experimental investigation of optical snow properties. Ann. Glaciol., 17 (see paper in this volume).

Stamnes, K., S. Tsay, W. Wiscombe and K. Jayaweera. 1988. Numerically sta.ble algorithm for discreteordinate-method radiative transfer in multiple scattering and emitting layered media. Appl. Opt., 27, 25022509.

Tanré, D. and 6 others. 1986. Simulation of the satellite signal in the solar spectrum. Villeneuve d'Asq, Laboratoire d'Optique Atmosphérique.
Warren, S. G. 1982. Optical properties of snow. Rev. Geophys. Space Phys., 20(1), 67-89.

Warren, S. G. and W.J. Wiscombe. 1980. A model for the spectral albedo of snow. II. Snow containing atmospheric aerosols. F. Atmos. Sci., 37(12), 2734-2745.

Warren, S. G., T. C. Grenfell and P. C. Mullen. 1986. Optical properties of Antarctic snow. Antarct. F. U. S., 21(5), 247-248.

Wiscombe, W.J. and S. G. Warren. 1980. A model for the spectral albedo of snow. I. Pure snow. J. Atmos. Sci., 37(12), 2712-2733.

The accuracy of references in the text and in this list is the responsibility of the authors, to whom queries should be addressed. 